\title{
Reaching minimal clinically important difference in adult spinal deformity surgery: a comparison of patients from North America and Japan
}

\author{
Hideyuki Arima, MD, PhD, ${ }^{1-3}$ Steven D. Glassman, MD, ${ }^{1,2}$ Keith Bridwell, MD, ${ }^{4}$ Yu Yamato, MD, PhD, ${ }^{3}$ \\ Mitsuru Yagi, MD, PhD, ${ }^{5}$ Kota Watanabe, MD, PhD, ${ }^{5}$ Morio Matsumoto, MD, PhD, ${ }^{5}$ \\ Satoshi Inami, MD, PhD, ${ }^{6}$ Hiroshi Taneichi, MD, PhD, ${ }^{6}$ Yukihiro Matsuyama, MD, PhD, ${ }^{3}$ and \\ Leah Y. Carreon, MD, Msc ${ }^{1,2}$ \\ ${ }^{1}$ Norton Leatherman Spine Center, Louisville, Kentucky; ${ }^{2}$ Department of Orthopedic Surgery, University of Louisville School of \\ Medicine, Louisville, Kentucky; ${ }^{3}$ Department of Orthopaedic Surgery, Hamamatsu University School of Medicine, Hamamatsu, \\ Shizuoka, Japan; ${ }^{4}$ Washington University in St. Louis, Missouri; ${ }^{5}$ Department of Orthopedic Surgery, Keio University School of \\ Medicine, Tokyo, Japan; and ${ }^{6}$ Department of Orthopaedic Surgery, Dokkyo Medical University, Tochigi, Japan
}

OBJECTIVE The Scoliosis Research Society-22r questionnaire (SRS-22r) has been shown to be reliable, valid, and responsive to change in patients with adult spinal deformity (ASD) undergoing surgery. The minimal clinically important difference (MCID) is the smallest difference in a health-related quality of life score that is considered to be worthwhile or clinically important to the individual. The authors hypothesized that the proportion of patients with ASD achieving an MCID in the SRS-22r score would be different between two culturally different cohorts. The purpose of this study was to compare the proportion of patients with ASD achieving MCID for the SRS-22r domains in North American (NA) and Japanese cohorts.

METHODS A total of 137 patients from North America (123 women, mean age 60.0 years) and 60 patients from Japan (56 women, mean age 65.5 years) with at least 2 years of follow-up after corrective spine surgery for ASD were included. Except for self-image, published Japanese MCID values of SRS-22r for ASD were higher (function = 0.90, pain $=0.85$, self-image $=1.05$, subtotal $=1.05$ ) than the published NA MCID values (function $=0.60$, pain $=0.40$, self-image $=1.23$, subtotal $=0.43$ ).

RESULTS There was a statistically significant improvement in all SRS-22r domain scores at 2 years compared to baseline in both cohorts. Except for mental health (NA $=0.32$, Japanese $=0.72, p=0.005$ ), the mean improvement from baseline to 2 years was similar between the NA and Japanese cohorts. The proportion of patients achieving MCID was higher in North America for function (NA $=51 \%$, Japanese $=30 \%, p=0.006$ ), pain (NA $=80 \%$, Japanese $=47 \%, p<$ $0.001)$, and subtotal (NA $=72 \%$, Japanese $=35 \%, p<0.001)$, while there was no significant difference for self-image (NA $=53 \%$, Japanese $=58 \%, p=0.454$ ).

CONCLUSIONS Despite similar improvements in SRS-22r domain scores from baseline to 2 years postoperatively, the proportion of patients reaching SRS-22r MCID for function, pain, and subtotal after ASD surgery was higher in the NA cohort than in the Japanese cohort. This may imply that patients in North America and Japan may value observed changes in clinical status differently.

https://thejns.org/doi/abs/10.3171/2019.12.SPINE19593

KEYWORDS minimum clinically important difference; adult spinal deformity; adult scoliosis; Scoliosis Research Society-22r; cultural difference

ABBREVIATIONS ADLs = activities of daily living; $A S D=$ adult spinal deformity; $H R Q O L$ = health-related quality of life; $L L=$ lumbar lordosis; $M C I D=$ minimal clinically important difference; NA = North American; PI = pelvic incidence; $P R O=$ patient-reported outcome; $P T=$ pelvic tilt; SRS-22r = Scoliosis Research Society-22r questionnaire; SVA = sagittal vertical axis; UIV = upper instrumented vertebra. SUBMITTED May 26, 2019. ACCEPTED December 2, 2019. INCLUDE WHEN CITING Published online January 31, 2020; DOI: 10.3171/2019.12.SPINE19593. 
$\mathrm{S}$ PINAL deformity due to lumbar spine degeneration is accompanied by coronal and/or sagittal plane malalignment and low-back pain, affecting activities of daily living (ADLs), standing posture, and cosmesis. Radiological parameters have historically been used in the evaluation of spinal deformity. In recent years, patientreported outcomes (PROs) have been regarded as a more relevant measure of treatment effectiveness. Several studies have reported that the Scoliosis Research Society-22r questionnaire (SRS-22r) is reliable, valid, and responsive to change in patients undergoing surgery, not only for adolescent idiopathic scoliosis but also for adult spinal deformity (ASD) ${ }^{6-9,11}$

Generally, a statistically significant difference between PROs before and after surgery is interpreted as a measure of treatment effectiveness. However, the differences measured between these groups may not be clinically relevant to the individual patient. The minimal clinically important difference (MCID) is the smallest difference in a healthrelated quality of life (HRQOL) score that is considered to be worthwhile or clinically important to the individual. ${ }^{17}$ The MCID of the SRS-22r for ASD has been calculated in cohorts from North America and corresponds to values of 0.60 for activity, 0.40 for pain, and 1.23 for self-image. ${ }^{13}$ We also calculated the SRS-22r MCID in a Japanese cohort using the same method. We found that MCID values for activity and pain were higher in a Japanese cohort. ${ }^{4}$ We hypothesized that the proportion of patients with ASD achieving an MCID in the SRS-22r score would differ between North American (NA) and Japanese cohorts. The purpose of this study is to report and compare the percentage of patients with ASD who reach a culturally specific SRS-22r MCID in NA and Japanese cohorts.

\section{Methods}

\section{Study Sample}

We compared 2 databases in this study. One was a prospective surgical database conducted at 9 medical centers in North America (US and Canada) in which patients with ASD between the ages of 40 and 80 years who had a lumbar curve with coronal Cobb angle $\geq 30^{\circ}$ and had either an Oswestry Disability Index score $\geq 20$ or an SRS-22r score $\leq 4$ in the domains of pain, function, and/or self-image were included. The second population was drawn from a retrospective study of consecutive cases of ASD with the same criteria from 3 institutions in Japan. Prior thoracic or lumbar fusion, as well as prior multilevel thoracolumbar decompression, were exclusion criteria in both cohorts. IRB approval was obtained at each site for the patient enrollment and data collection protocols. IRB approval was also obtained for this secondary analysis.

\section{Radiographic Evaluation}

Thirty-six-inch standing anteroposterior and lateral spine radiographs obtained preoperatively and 2 years postoperatively were analyzed. The spinopelvic parameters of lumbar lordosis (LL, Cobb angle between the superior endplate of L1 and the superior endplate of S1), pelvic tilt (PT, the angle subtended by a vertical reference line originating from the center of the femoral heads and the midpoint of the sacral endplate), the mismatch between pelvic incidence (PI, the angle between the line perpendicular to the sacral plate at its midpoint and the line connecting this point to the femoral head axis) and LL (PI-LL), and sagittal vertical axis (SVA, C7 plumb line relative to S1) were measured using standard techniques.., 20

\section{PRO Measures}

PROs were evaluated with the SRS-22r, a scoliosis-specific HRQOL questionnaire with 22 items and 5 domains: activity, pain, self-image, mental, and satisfaction, and a total score. ${ }^{16}$ Each domain score ranges from 1 to 5, with higher scores indicating better outcomes. ${ }^{5-7}$ The SRS-22r has been shown to be responsive, reliable, and valid in populations with ASD. ${ }^{8,9,11}$

\section{MCID Threshold Value Between North America and Japan}

The MCID of the SRS-22r for ASD has already been calculated in an NA database (function $=0.60$, pain $=0.40$, self-image $=1.23$, subtotal $=0.43) \cdot{ }^{13} \mathrm{We}$ also calculated the SRS-22r MCID in a Japanese cohort using a similar method (function $=0.90$, pain $=0.85$, self-image $=1.05$, and subtotal $=1.05) .{ }^{4}$ We compared the proportion of patients achieving SRS-22r MCID value at 2 years' follow-up.

\section{Propensity-Score Matching}

To investigate the potential difference in the proportion of patients achieving SRS-22r MCID value at 2 years' follow-up, patients were propensity-matched by age, sex, number of fused vertebrae, and spinopelvic morphology (SVA, PI-LL, and PT) at baseline (Fig. 1). Propensity scores were calculated by linear regression analysis.

\section{Results \\ Demographics}

A total of 197 patients were included in this study: 137 cases from the NA population (123 women, mean age 60.0 years) and 60 cases from the Japanese population (56 women, mean age 65.5 years) with at least 2 years' followup after corrective spine surgery for ASD. The mean age was significantly older in the Japanese cohort $(p<0.001)$, and the BMI was significantly lower in the Japanese cohort $\left(\mathrm{NA}=26.9 \mathrm{~kg} / \mathrm{m}^{2}\right.$, Japanese $=21.5 \mathrm{~kg} / \mathrm{m}^{2}, \mathrm{p}<0.001$; Table 1).

\section{Surgical Details}

The mean number of fused vertebrae was significantly more in the NA group (NA $=12.2$, Japanese $=9.7, \mathrm{p}<$ 0.001 ; Table 2). In both groups, most of the cases involved fusion to the sacrum or pelvis, and the upper instrumented vertebra (UIV) was the more cranial level in the NA group. The ratio of anterior spinal fusion was significantly higher in the Japanese group $(\mathrm{NA}=5.8 \%$, Japanese $=$ $15.0 \%, \mathrm{p}<0.001$; Table 2).

\section{Radiographic Parameters}

Regarding the sagittal parameters, the PI-LL value was significantly lower in the Japanese group at baseline (NA $=17.3^{\circ}$, Japanese $\left.=36.1^{\circ}, \mathrm{p}<0.001\right)$, and the SVA was shifted forward $(\mathrm{NA}=31.2 \mathrm{~mm}$, Japanese $=82.8 \mathrm{~mm}, \mathrm{p}<$ 


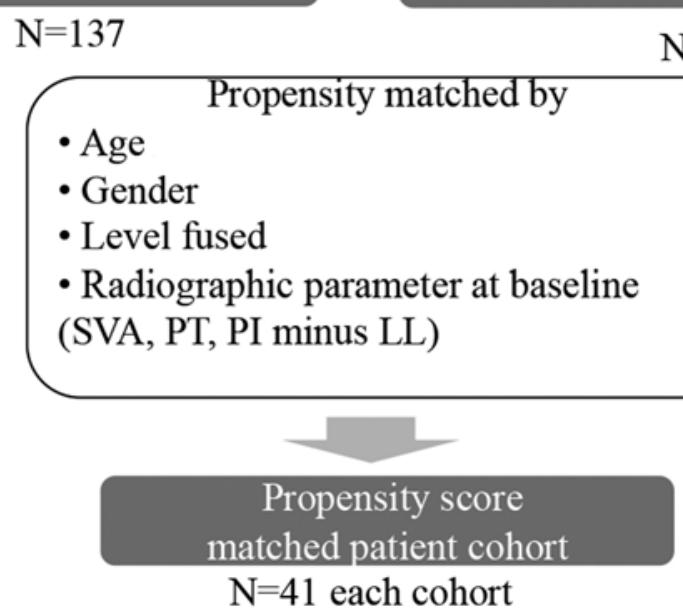

FIG. 1. A flowchart for propensity-score matching subanalysis.

0.001; Table 3). At 2 years' follow-up, all sagittal parameters significantly improved in both groups $(\mathrm{p}<0.001)$, but the PI-LL remained significantly worse in the Japanese group $\left(\mathrm{NA}=4.1^{\circ}\right.$, Japanese $\left.=11.8^{\circ}, \mathrm{p}=0.001\right)$ and the SVA was shifted forward (NA $=13.3 \mathrm{~mm}$, Japanese $=46.8$ $\mathrm{mm}, \mathrm{p}<0.001$; Table 3$)$. The Cobb angle was significantly better in the NA group at baseline $\left(\mathrm{NA}=57.1^{\circ}\right.$, Japanese $=$ $49.1^{\circ}, \mathrm{p}=0.001$ ) and significantly improved in both groups after surgery $(\mathrm{p}<0.001$; Table 3$)$.

\section{PROs}

There was a statistically significant improvement in all SRS-22r domain scores at the 2-year follow-up compared to baseline in both cohorts (Table 4). Except for mental health $(\mathrm{NA}=0.32$, Japanese $=0.72, \mathrm{p}=0.005)$, the mean improvement from baseline to 2 years was similar between the NA and Japanese cohorts. However, 2-year follow-up SRS-22r satisfaction was higher in the NA cohort than in the Japanese cohort $(\mathrm{NA}=4.50$, Japanese $=$ 3.61, $\mathrm{p}<0.001)$.

\section{Proportion of ASD Patients Achieving SRS-22r MCID}

Except for self-image $(\mathrm{NA}=53 \%$, Japanese $=58 \%, \mathrm{p}$ $=0.454$ ), the proportion of patients achieving MCID was higher in the NA cohorts for function (NA $=51 \%$, Japanese $=30 \%, \mathrm{p}=0.006)$, pain $(\mathrm{NA}=80 \%$, Japanese $=47 \%$, $\mathrm{p}<0.001)$, and subtotal $(\mathrm{NA}=72 \%$, Japanese $=35 \%, \mathrm{p}<$ 0.001 ; Table 5).

\section{Propensity-Score Matching Analysis}

We identified 82 patients (41 patients each in the NA and Japanese cohorts) with matched propensity scores within these parameters: age (mean $63.2 \pm 8.7$ years vs $63.9 \pm 10.2$ years), female ratio $(92.7 \%$ vs $90.2 \%)$, number of fused vertebrae (mean $10.4 \pm 3.0$ vs $10.0 \pm 2.1$ ), SVA at baseline $(51.8 \pm 53.8 \mathrm{~mm}$ vs $52.1 \pm 45.1 \mathrm{~mm})$, PI-LL at baseline (mean $26.7^{\circ} \pm 15.3^{\circ}$ vs $28.4^{\circ} \pm 19.0^{\circ}$ ), and PT at baseline $\left(28.4^{\circ} \pm 9.3^{\circ}\right.$ vs $28.1^{\circ} \pm 10.0^{\circ}$; Table 6). Except for self-image $(\mathrm{NA}=46 \%$, Japanese $=56 \%, \mathrm{p}=0.508)$, the proportion of patients achieving MCID was still higher in the NA cohorts for function $(\mathrm{NA}=61 \%$, Japanese $=34 \%, \mathrm{p}$ $=0.026)$, pain $(\mathrm{NA}=90 \%$, Japanese $=44 \%, \mathrm{p}<0.001)$, and subtotal $(\mathrm{NA}=76 \%$, Japanese $=37 \%, \mathrm{p}=0.001$; Table 6$)$.

\section{Discussion}

In patients with ASD, the trunk tilts forward as the lumbar spine becomes kyphotic. Because the center of gravity deviates from the lower limb/pelvic plumb line, more energy is required to maintain upright posture and walk long distances. The effect of nonsurgical treatment is limited. ${ }^{14}$ Surgical correction of the spinal deformity is one method to improve HRQOL in patients with severe ASD. ${ }^{21,22}$ The purpose of corrective surgery for ASD is to improve patients' pain and daily function. As PROs reflect the patient's perception of pain and function, they are commonly used to evaluate the impact of the spine deformity on a patient's quality of life.

Differences in the value system in distinct cultures may affect what a patient deems is important in his or her daily life. An equal improvement in PROs in two different countries may be differently valued by patients with distinct cultural and social backgrounds. The results of the current study showed that a significantly greater proportion of patients in North America achieve an MCID for pain and function compared to patients in Japan. One reason for this is that MCID values for the SRS-22r function and pain domains are lower in North America.

TABLE 1. Demographics

\begin{tabular}{lccr}
\hline \multicolumn{1}{c}{ Variable } & North America & Japan & p Value \\
\hline No. of patients & 137 & 60 & \\
\hline Mean age (SD), yrs & $60.0(8.6)$ & $65.5(9.4)$ & $<0.001$ \\
\hline Women, $\mathrm{n}(\%)$ & $123(90)$ & $56(93.3)$ & 0.428 \\
\hline Mean BMl (SD), $\mathrm{kg} / \mathrm{m}^{2}$ & $26.9(4.8)$ & $21.5(2.7)$ & $<0.001$ \\
\hline
\end{tabular}


TABLE 2. Surgical details

\begin{tabular}{|c|c|c|c|}
\hline Surgical Variable & North America & Japan & $p$ Value \\
\hline Mean no. of fused vertebrae & 12.2 & 9.7 & $<0.001$ \\
\hline UIV level, $n$ & & & $<0.001$ \\
\hline $\mathrm{T} 1$ & 1 & 0 & \\
\hline $\mathrm{T} 2$ & 12 & 1 & \\
\hline T3 & 21 & 0 & \\
\hline T4 & 23 & 1 & \\
\hline T5 & 11 & 3 & \\
\hline T6 & 0 & 3 & \\
\hline $\mathrm{T7}$ & 0 & 1 & \\
\hline T8 & 3 & 5 & \\
\hline T9 & 10 & 13 & \\
\hline T10 & 42 & 24 & \\
\hline $\mathrm{T} 11$ & 9 & 7 & \\
\hline $\mathrm{T} 12$ & 2 & 1 & \\
\hline L1 & 2 & 0 & \\
\hline L2 & 1 & 1 & \\
\hline LIV level, $n$ & & & 0.196 \\
\hline L2 & 0 & 1 & \\
\hline L3 & 1 & 0 & \\
\hline L4 & 6 & 1 & \\
\hline L5 & 2 & 8 & \\
\hline S1 or pelvis & 128 & 50 & \\
\hline Anterior spinal fusion & $5.8 \%$ & $15.0 \%$ & $<0.001$ \\
\hline
\end{tabular}

LIV = lower instrumented vertebra.

In addition, the pathology of deformity may be different between Japan and North America. ASD has been reported as an aggregation of heterogeneous diseases. ${ }^{23}$ Therefore, it is difficult to regard this as a single condition. In this study, patients 40 years of age and older and with a scoliosis curvature angle $>30^{\circ}$ were included, and cases with previous spinal fusion surgery were excluded in order to create homogeneous cohorts. Nevertheless, the sagittal radiographic parameters still differed greatly between the Japanese and NA cohorts at baseline and at follow-up. Hosogane et al. also reported that Japan showed significantly worse sagittal alignment such as smaller LL and larger SVA than the US at baseline. ${ }^{18}$ Ames et al. reported that approximately $34 \%$ of their study population with ASD surgery was young with coronal plane deformity, and $27 \%$ was older with prior spine surgeries in European and NA ASD databases. ${ }^{2}$ Conversely, Arima et al. reported that $18 \%$ of their ASD population was young with coronal plane deformity and 6\% was older with prior spine surgeries. ${ }^{4}$ These differences suggest that the pathology of ASD is different between North America and Japan. Different disease states have different severities at baseline. In addition, the severity of symptoms at baseline can also influence the MCID value. ${ }^{12}$ As reported by Arima et al., the SRS-22r MCID values for ASD surgery in Japan were reported to be higher than those in North America. ${ }^{4}$ Therefore, there is a possibility that the difference in pathologies between both groups may be related to differences in achieving MCIDs.

Although it is such a heterogeneous group, it is interesting to note that the amount of change in SRS-22r domain scores was similar between Japan and North America, i.e., the degree of clinical improvement was similar in both groups. However, the NA group showed an increased perception of treatment improvement. The high degree of postoperative satisfaction in the NA cohort also supports the higher awareness of treatment improvement in the NA cohort than in the Japanese cohort.

In this study, a subanalysis was also performed using propensity-score matching analysis to mitigate the difference between the two cohorts at these baselines. As a result, the proportion of patients achieving MCID was higher in the NA cohort, with the exception of self-image.

In patients who have undergone a spinal fusion over several segments, there are many motions that are limited, such as putting on socks and performing ADLs on the floor. ${ }^{23}$ As the Japanese lifestyle is floor-based, Japanese patients may feel more restrictions in their daily living after surgery than patients in North America. Togawa et al. previously reported that elderly patients with ASD in Japan have very limited ability to pick things up from the floor and get down on all four limbs. ${ }^{23}$ These limitations should be discussed with patients prior to their surgery. In addition, the health insurance system and postoperative regimen are different in these two countries. The differences between the health insurance system and patient satisfaction have been reported previously. ${ }^{10}$ There are also reports that American patients have higher patient satisfaction than Japanese patients; ${ }^{19}$ therefore, these differences also may have affected MCID achievement.

Our study has several limitations. First, the MCID val-

TABLE 3. Comparison among preoperative and 2-year postoperative radiographic parameters in North America and Japan

\begin{tabular}{|c|c|c|c|c|c|c|c|c|}
\hline \multirow[b]{2}{*}{ Parameter } & \multicolumn{3}{|c|}{ North America } & \multicolumn{3}{|c|}{ Japan } & \multicolumn{2}{|c|}{ North America \& Japan } \\
\hline & Preop & 2-Yr Postop & p Value* & Preop & 2-Yr Postop & p Value* & $\begin{array}{l}\text { Preop } \\
\text { p Values }\end{array}$ & $\begin{array}{c}\text { 2-Yr Postop } \\
\text { p Values }\end{array}$ \\
\hline SVA, mm & $31.2(41.7)$ & $13.3(36.7)$ & $<0.001$ & $82.8(65.4)$ & $46.8(48.5)$ & $<0.001$ & $<0.001$ & $<0.001$ \\
\hline $\mathrm{Pl}-\mathrm{LL},{ }^{\circ}$ & $17.3(17.1)$ & $4.1(13.4)$ & $<0.001$ & $36.1(21.1)$ & $11.8(15.5)$ & $<0.001$ & $<0.001$ & 0.001 \\
\hline PT, ${ }^{\circ}$ & $23.9(8.8)$ & $21.1(19.4)$ & $<0.001$ & $34.0(13.2)$ & $26.6(11.6)$ & $<0.001$ & $<0.001$ & 0.001 \\
\hline Cobb angle, ${ }^{\circ}$ & $57.1(14.9)$ & $26.5(12.1)$ & $<0.001$ & $49.1(16.6)$ & $17.6(10.7)$ & $<0.001$ & 0.001 & $<0.001$ \\
\hline
\end{tabular}

Data given as mean (SD) or $p$ value. Boldface type indicates statistical significance.

* Comparison between preoperative and 2-year postoperative values. 
TABLE 4. Comparisons among preoperative and 2-year postoperative SRS-22r domain scores in North America and Japan

\begin{tabular}{|c|c|c|c|c|c|c|c|c|c|}
\hline \multirow[b]{2}{*}{ Domain } & \multicolumn{4}{|c|}{ North America } & \multicolumn{4}{|c|}{ Japan } & \multirow[b]{2}{*}{$\begin{array}{c}\text { North America \& } \\
\text { Japan p Values }\end{array}$} \\
\hline & $\begin{array}{l}\text { Mean Preop } \\
\text { (SD) }\end{array}$ & $\begin{array}{l}\text { Mean 2-Yr } \\
\text { Postop (SD) }\end{array}$ & $\begin{array}{l}\text { 2-Yr Change } \\
\text { From Preop }\end{array}$ & p Value* & $\begin{array}{l}\text { Mean Preop } \\
\text { (SD) }\end{array}$ & $\begin{array}{l}\text { Mean 2-Yr } \\
\text { Postop (SD) }\end{array}$ & $\begin{array}{l}\text { 2-Yr Change } \\
\text { From Preop }\end{array}$ & p Value* & \\
\hline Function & $3.18(0.69)$ & $3.67(0.70)$ & 0.49 & $<0.001$ & $2.76(0.83)$ & $3.3(0.80)$ & 0.54 & $<0.001$ & $0.618 \dagger$ \\
\hline Pain & $2.83(0.72)$ & $3.83(0.80)$ & 1.00 & $<0.001$ & $2.82(0.86)$ & $3.69(0.86)$ & 0.87 & $<0.001$ & $0.343 \dagger$ \\
\hline Self-image & $2.74(0.65)$ & $4.02(0.73)$ & 1.28 & $<0.001$ & $2.33(0.83)$ & $3.44(0.78)$ & 1.11 & $<0.001$ & $0.334 \dagger$ \\
\hline Mental health & $3.72(0.77)$ & $4.07(0.74)$ & 0.32 & $<0.001$ & $2.66(0.67)$ & $3.38(0.79)$ & 0.72 & $<0.001$ & $0.005 \dagger$ \\
\hline Subtotal & $3.14(0.52)$ & $3.91(0.60)$ & 0.58 & $<0.001$ & $2.64(0.59)$ & $3.45(0.66)$ & 0.68 & 0.009 & $0.635 \dagger$ \\
\hline Satisfaction & - & $4.50(0.65)$ & - & - & - & $3.61(0.90)$ & - & - & $<0.001 \ddagger$ \\
\hline
\end{tabular}

Boldface type indicates statistical significance.

* Comparison between preoperative and 2-year postoperative values.

† Comparison of 2-year change values.

$\ddagger$ Comparison of 2-year postoperative values.

ues in the NA cohort were calculated using 1-year followup data, whereas the Japanese MCID values were calculated using 2-year postoperative follow-up data. It was reported that the postoperative change in PROs of ASD had stabilized after a 1-year postoperative interval in the NA cohort. ${ }^{15}$ Therefore, the difference in the follow-up period between the cohorts may not significantly affect the study results. Second, we did not take into account differences in the pathology of ASD when we compared the proportion of patients who reached the SRS-22r MCID between the NA and Japanese cohorts. As previously reported, some differences in the severity of deformity, as measured by SRS-Schwab sagittal modifier grading, ${ }^{1}$ were found between the two populations, and these differences may be related to the variation in the proportion of patients who achieved the SRS-22r MCID. Third, the NA cohort was part of a prospective study, and the Japanese cohort was from a retrospectively analyzed database that was prospectively collected. These differences in study design may affect patients' expectations because the NA cohort knew they were being studied. Fourth, we did not administer an SRS-30 questionnaire in this cohort. Therefore, we were unable to calculate new MCID values in this cohort and verify previously reported MCID values. Fifth, intra- and interobserver reliability of the radiographic parameters was not measured. Sixth, the demographics (age and BMI) differed between the cohorts, which could have impacted the results. Despite these limitations, these cultural differences in the proportion of patients reaching SRS-22r MCID for ASD surgical cases have important implications.

TABLE 5. Proportion of patients with ASD achieving SRS-22r $M C I D$ in North America and Japan

\begin{tabular}{cccc}
\hline SRS-22r Domain & North America (\%) & Japan (\%) & p Value \\
\hline Function & 51 & 30 & 0.006 \\
\hline Pain & 80 & 47 & $<0.001$ \\
\hline Self-image & 53 & 58 & 0.454 \\
\hline Subtotal & 72 & 35 & $<0.001$ \\
\hline
\end{tabular}

\section{Conclusions}

Despite similar improvements in SRS-22r domain scores from baseline to 2 years postoperatively, the proportion of patients reaching SRS-22r MCID for function, pain, and subtotal domains after ASD surgery was higher in an NA cohort compared to a Japanese cohort. This finding may imply that patients in North America and Japan may regard the value of these changes differently.

\section{Acknowledgments}

Funds were received from the National Institute of Arthritis and Musculoskeletal and Skin Diseases in support of this work (grant no. 5R01AR055176-03). We would like to acknowledge Christopher Shaffrey, MD, Oheneba Boachie-Adjei, MD, Stefan Parent, MD, Stephen Lewis, MD, Tyler Koski, MD, Charles Edwards II, MD, Frank Schwab, MD, Jacob Buchowski, MD, Charles H. Crawford III, MD, Han Jo Kim, MD, Lawrence G. Lenke, MD, and Justin Smith, MD, for contributing patients to the study.

TABLE 6. Demographic, radiographic, and HRQOL in propensity-matched cohort

\begin{tabular}{|c|c|c|c|}
\hline Variable & $\begin{array}{l}\text { North } \\
\text { America }\end{array}$ & Japan & p Value \\
\hline Mean age (SD), yrs & $63.2(8.7)$ & $63.9(10.2)$ & 0.763 \\
\hline Female, $\%$ & $92.7 \%$ & $90.2 \%$ & 0.697 \\
\hline Mean no. of fused vertebrae (SD) & $10.4(3.0)$ & $10.0(2.1)$ & 0.454 \\
\hline Mean SVA at baseline (SD), mm & $51.8(53.8)$ & $52.1(45.1)$ & 0.979 \\
\hline Mean PI-LL at baseline (SD), ${ }^{\circ}$ & $26.7(15.3)$ & $28.4(19.0)$ & 0.660 \\
\hline Mean PT at baseline (SD), ${ }^{\circ}$ & $28.4(9.3)$ & $28.1(10.0)$ & 0.892 \\
\hline \multicolumn{4}{|l|}{$\begin{array}{l}\text { Proportion of ASD patients } \\
\text { achieving SRS-22r MCID (\%) }\end{array}$} \\
\hline Function & 61 & 34 & 0.026 \\
\hline Pain & 90 & 44 & $<0.001$ \\
\hline Self-image & 46 & 56 & 0.508 \\
\hline Subtotal & 76 & 37 & 0.001 \\
\hline
\end{tabular}

Boldface type indicates statistical significance. 


\section{References}

1. Ames C, Gammal I, Matsumoto M, Hosogane N, Smith JS, Protopsaltis T, et al: Geographic and ethnic variations in radiographic disability thresholds: analysis of North American and Japanese operative adult spinal deformity populations. Neurosurgery 78:793-801, 2016

2. Ames CP, Smith JS, Pellisé F, Kelly M, Alanay A, Acaroğlu E, et al: Artificial intelligence based hierarchical clustering of patient types and intervention categories in adult spinal deformity surgery: towards a new classification scheme that predicts quality and value. Spine (Phila Pa 1976) 44:915926, 2019

3. Ames CP, Smith JS, Scheer JK, Bess S, Bederman SS, Deviren $\mathrm{V}$, et al: Impact of spinopelvic alignment on decision making in deformity surgery in adults: a review. J Neurosurg Spine 16:547-564, 2012

4. Arima H, Carreon LY, Glassman SD, Yamato Y, Hasegawa T, Togawa D, et al: Cultural variations in the minimum clinically important difference thresholds for SRS-22R after surgery for adult spinal deformity. Spine Deform 7:627-632, 2019

5. Asher M, Min Lai S, Burton D, Manna B: Discrimination validity of the Scoliosis Research Society-22 patient questionnaire: relationship to idiopathic scoliosis curve pattern and curve size. Spine (Phila Pa 1976) 28:74-78, 2003

6. Asher M, Min Lai S, Burton D, Manna B: The reliability and concurrent validity of the Scoliosis Research Society-22 patient questionnaire for idiopathic scoliosis. Spine (Phila Pa 1976) 28:63-69, 2003

7. Asher M, Min Lai S, Burton D, Manna B: Scoliosis Research Society-22 patient questionnaire: responsiveness to change associated with surgical treatment. Spine (Phila Pa 1976) 28:70-73, 2003

8. Baldus C, Bridwell KH, Harrast J, Edwards C II, Glassman S, Horton W, et al: Age-gender matched comparison of SRS instrument scores between adult deformity and normal adults: are all SRS domains disease specific? Spine (Phila Pa 1976) 33:2214-2218, 2008

9. Berven S, Deviren V, Demir-Deviren S, Hu SS, Bradford DS: Studies in the modified Scoliosis Research Society Outcomes Instrument in adults: validation, reliability, and discriminatory capacity. Spine (Phila Pa 1976) 28:2164-2169, 2003

10. Blendon RJ, Leitman R, Morrison I, Donelan K: Satisfaction with health systems in ten nations. Health Aff (Millwood) 9:185-192, 1990

11. Bridwell KH, Berven S, Glassman S, Hamill C, Horton WC III, Lenke LG, et al: Is the SRS-22 instrument responsive to change in adult scoliosis patients having primary spinal deformity surgery? Spine (Phila Pa 1976) 32:2220-2225, 2007

12. Copay AG, Subach BR, Glassman SD, Polly DW Jr, Schuler TC: Understanding the minimum clinically important difference: a review of concepts and methods. Spine J 7:541-546, 2007

13. Crawford CH III, Glassman SD, Bridwell KH, Berven SH, Carreon LY: The minimum clinically important difference in SRS-22R total score, appearance, activity and pain domains after surgical treatment of adult spinal deformity. Spine (Phila Pa 1976) 40:377-381, 2015

14. Glassman SD, Carreon LY, Shaffrey CI, Polly DW, Ondra SL, Berven SH, et al: The costs and benefits of nonoperative management for adult scoliosis. Spine (Phila Pa 1976) 35:578-582, 2010

15. Glassman SD, Schwab F, Bridwell KH, Shaffrey C, Horton W, Hu S: Do 1-year outcomes predict 2-year outcomes for adult deformity surgery? Spine J 9:317-322, 2009

16. Hashimoto H, Sase T, Arai Y, Maruyama T, Isobe K, Shouno Y: Validation of a Japanese version of the Scoliosis Research Society-22 Patient Questionnaire among idiopathic scoliosis patients in Japan. Spine (Phila Pa 1976) 32:E141-E146, 2007

17. Hays RD, Woolley JM: The concept of clinically meaning- ful difference in health-related quality-of-life research. How meaningful is it? Pharmacoeconomics 18:419-423, 2000

18. Hosogane N, Ames C, Matsumoto M, Yagi M, Matsuyama Y, Taneichi H, et al: Ethnic variations in radiographic parameters and SRS-22 scores in adult spinal deformity: a comparison between North American and Japanese patients above 50 years of age with minimum 2-year follow-up. Clin Spine Surg 31:216-221, 2018

19. Kurata JH, Watanabe Y, McBride C, Kawai K, Andersen R: A comparative study of patient satisfaction with health care in Japan and the United States. Soc Sci Med 39:1069-1076, 1994

20. O'Brien M, Kuklo T, Blanke K, Lenke L: Spinal Deformity Study Group Radiographic Measurement Manual. Memphis: Medtronic Sofamor Danek USA, 2005

21. Sciubba DM, Scheer JK, Yurter A, Smith JS, Lafage V, Klineberg E, et al: Patients with spinal deformity over the age of 75: a retrospective analysis of operative versus nonoperative management. Eur Spine J 25:2433-2441, 2016

22. Smith JS, Lafage V, Shaffrey CI, Schwab F, Lafage R, Hostin R, et al: Outcomes of operative and nonoperative treatment for adult spinal deformity: a prospective, multicenter, propensity-matched cohort assessment with minimum 2-year follow-up. Neurosurgery 78:851-861, 2016

23. Togawa D, Hasegawa T, Yamato Y, Yoshida G, Kobayashi S, Yasuda T, et al: Postoperative disability after long corrective fusion to the pelvis in elderly patients with spinal deformity. Spine (Phila Pa 1976) 43:E804-E812, 2018

\section{Disclosures}

Dr. Glassman reports being an employee of Norton Healthcare; being a consultant for K2M and Medtronic; receiving royalties from Medtronic; receiving clinical or research support for the study from NuVasive; and being a patent holder for Medtronic. Dr. Carreon reports being an employee of Norton Healthcare; receiving funds for travel from the University of Southern Denmark and the University of Louisville; that her institution received research funds from OREF, NIH, ISSG, SRS, TSRH, Pfizer, LifeSciences Corp., IntelliRod, Cerapedics, Medtronic, Empirical Spine, and the NeuroPoint Alliance; being a member of the Editorial Advisory Board of Spine Deformity, The Spine Journal, and Spine; and being a member of the University of Louisville IRB and the Research Committee of the SRS.

\section{Author Contributions}

Conception and design: Arima, Glassman, Carreon. Acquisition of data: Arima, Bridwell, Yamato, Yagi, Watanabe, Matsumoto, Inami, Taneichi, Matsuyama, Carreon. Analysis and interpretation of data: Arima, Glassman, Bridwell, Carreon. Drafting the article: Arima. Critically revising the article: Arima, Glassman, Yagi, Watanabe, Matsumoto, Inami, Taneichi, Matsuyama, Carreon. Reviewed submitted version of manuscript: Arima, Glassman, Yamato, Yagi, Watanabe, Matsumoto, Inami, Taneichi, Matsuyama, Carreon. Approved the final version of the manuscript on behalf of all authors: Arima. Statistical analysis: Arima, Carreon. Study supervision: Glassman, Bridwell, Matsuyama, Carreon.

\section{Supplemental Information}

\section{Previous Presentations}

This study was presented as an e-poster at the 34th Annual Meeting of the North American Spine Society, September 24-29, 2018, in Los Angeles, California.

\section{Correspondence}

Hideyuki Arima: Norton Leatherman Spine Center, Louisville, KY. arihidee@gmail.com. 